\title{
Does isolation influence the relative role of environmental and dispersal-related processes in stream networks? An empirical test of the network position hypothesis using multiple taxa
}

\author{
Dénes Schmera $^{1,2}$ (D) | Diána Árva ${ }^{1}$ | Pál Boda ${ }^{2,3}$ | Erika Bódis ${ }^{4}$ | Ágnes Bolgovics ${ }^{3,5}$ | \\ Gábor Borics $^{2,3}$ | András Csercsa ${ }^{3,6}$ | Csaba Deák ${ }^{7}$ | Eszter Á. Krasznai ${ }^{3,6}$ | Balázs A. \\ Lukács $^{2,3}$ | Péter Mauchart ${ }^{8}$ | Arnold Móra ${ }^{1,8}$ | Péter Sály ${ }^{1,8}$ | András Specziár ${ }^{1}$ | \\ Kristóf Süveges $^{9}$ | Ildikó Szivák ${ }^{1,2}$ | Péter Takács ${ }^{1}$ | Mónika Tóth ${ }^{1,2}$ | \\ Gábor Várbíró $^{2,3}$ | Anna E. Vojtkó ${ }^{3}$ (D) | Tibor Erös ${ }^{1,2}$
}

${ }^{1}$ MTA Centre for Ecological Research, Balaton Limnological Institute, Tihany, Hungary

${ }^{2}$ GINOP Sustainable Ecosystems Group, MTA Centre for Ecological Research,

Tihany, Hungary

${ }^{3}$ Department of Tisza River Research, MTA Centre for Ecological Research, Danube Research Institute, Debrecen, Hungary

${ }^{4}$ MTA Centre for Ecological Research, Danube Research Institute, Budapest, Hungary

${ }^{5}$ Eötvös Loránd University, Budapest, Hungary

${ }^{6}$ Doctoral School of Chemistry and Environmental Sciences, University of Pannonia, Veszprém, Hungary

${ }^{7}$ National Inspectorate for Environmental Protection and Nature Conservation Management (Transtisza), Laboratory, Debrecen, Hungary

${ }^{8}$ Department of Hydrobiology, Faculty of Sciences, Institute of Biology, University of Pécs, Pécs, Hungary

${ }^{9}$ Department of Botany, University of Debrecen, Debrecen, Hungary

\section{Correspondence}

Tibor Erős, MTA Centre for Ecological Research, Balaton Limnological Institute, Tihany, Hungary.

Email: eros.tibor@okologia.mta.hu

Funding information

Országos Tudományos Kutatási Alapprogramok, Grant/Award Number: K104279; GINOP, Grant/Award Number: 2.3.3-15-2016-00019

\section{Abstract}

1. Quantifying the relative importance of how local (environmental or niche-based) and regional (dispersal-related or spatial) processes regulate the assembly of communities has become one of the main research avenues of community ecology. It has been shown that the degree of isolation of local habitats in the landscape may substantially influence the relative role of environmental filtering and dispersal-related processes in metacommunities.

2. Dendritic stream networks are unique habitats in the landscape, where more isolated upstream sites have been predicted to be primarily structured by environmental variables, while more central mainstem rivers by both environmental and spatial variables (hereafter the network position hypothesis, NPH). However, the $\mathrm{NPH}$ has almost exclusively been tested for stream macroinvertebrates, and therefore its predictions warrant confirmation from multiple taxa.

3. We examined the validity of the NPH for benthic diatoms, macrophytes, macroinvertebrates and fish in the Pannon Ecoregion, Hungary. Following the NPH we predicted a clear dominance of environmental over spatial variables in headwaters, and a larger effect of spatial variables in rivers compared to headwaters. We tested these predictions using variance partitioning analyses separately for the different taxa in headwater and in riverine habitats.

4. We found large differences in the explained community variance when the impact of environmental (physical and chemical) and spatial (overland and watercourse distance) variables for various taxa was studied. In general, total explained variance was lower for the more passively dispersing plant taxa than for animal taxa with more active dispersal in both streams and rivers. However, similar to other studies, the total explained variance was low for both headwater streams and rivers. 
5. Community structure of diatoms could be best explained by both environmental and spatial variables in streams, whereas their community structure could not be explained by either variable group in rivers. The significance of environmental and spatial variables depended on the distance measure (overland versus watercourse) in the case of macrophytes. Community structure of macroinvertebrates could be explained by environmental variables in streams and by both environmental and spatial variables in rivers. Moreover, variation was explained by different predictors when macroinvertebrate taxa were divided into flying and non-flying groups, suggesting the importance of dispersal mode in explaining community variation. Finally, community structure of fishes could be explained by both environmental and spatial variables in streams and only by environmental variables in rivers.

6. In conclusion, we found no clear evidence of the NPH in our multi-taxa comparison. For example, while patterns in macroinvertebrate communities seem to support the NPH, those in fish communities run counter with the predictions of the $\mathrm{NPH}$. This study thus shows that different taxa may behave differently to isolation effects in stream networks. We discuss alternatives in the interpretation of dispersal (or spatial) effects which may partly explain differences in the observed patterns from the NPH, and emphasise the need for further studies in unravelling the importance of isolation in stream metacommunity structuring.

KEYWORDS

dispersal, environmental variables, metacommunities, river ecosystems, spatial variables

\section{1 | INTRODUCTION}

Understanding the processes regulating the assembly of communities is fundamental to ecology and provides the basis for environmental management. While formal theories in community ecology focused mainly on understanding local scale patterns and processes, assuming that local communities are closed and isolated, recent research integrates ecological knowledge at different spatial scales to disentangle how local communities form from the regional species pool (Leibold et al., 2004; Meynard et al., 2013). The metacommunity concept (Gilpin \& Hanski, 1991), which addresses the situation where sets of local communities are linked by dispersal (Leibold et al., 2004), has proven to be a powerful approach for predicting how dispersal rates of organisms influences the relative importance of dispersal-related or spatial (hereafter we use these words interchangeably) and local scale (i.e. environmental or niche-based) processes in structuring communities (Heino et al., 2015; Logue, Mouquet, Peter, \& Hillebrand, 2011; Wienegardner, Jones, Ng, Siqueira, \& Cottenie, 2012). It has been suggested that if dispersal rates are below local extinction probabilities (dispersal limitation), then species will often be absent from otherwise environmentally suitable habitats (Leibold et al., 2004). If dispersal rates exceed local extinction probabilities, then sites will contain nearly all species in the region capable of invading the focal habitat. In such cases, species will be distributed in the landscape according to environmentally controlled or niche-based (i.e. species-sorting) mechanisms (Shurin, 2000). Finally, a high rate of dispersal might homogenise local communities by distributing species into all habitats irrespective of their suitability (i.e. mass effect), which may also increase the observed spatial signal (Urban et al., 2008). Thanks to the metacommunity approach, an increasing amount of studies suggest that the importance of local scale environmental and regional scale dispersalrelated processes may change among different ecosystems and habitat types (Cottenie, 2005; Heino et al., 2015; Logue et al., 2011; Sarremejane, Mykrä, Bonada, Aroviita, \& Muotka, 2017). The metacommunity concept thus revolutionises thinking on the assembly of ecological communities in both terrestrial and aquatic habitats (Heino, Soininen, Alahuhta, Lappalainen, \& Virtanen, 2017; Tonkin, Sundermann, Jahnig, \& Haase, 2015; Tonkin et al., 2017).

Dendritic stream networks are unique habitats in the landscape (Campbell Grant, Lowe, \& Fagan, 2007), where, beside the type of the habitat, spatial positioning can have critical importance in metacommunity organisation (Altermatt, 2013; Erős, Takács, Specziár, Schmera, \& Sály, 2017; Tonkin et al., 2015). Nevertheless, few direct tests exist that address how local scale and dispersal related processes interact with the spatial positioning of the habitat in determining the metacommunity organisation of stream organisms. In an influential paper, Brown and Swan (2010) proposed that the 
dendritic (hierarchically branching) feature of stream systems may substantially determine the relative role of environmental and dispersal-related processes in structuring communities depending on the position of the community within the stream network. They hypothesised that headwater streams are environmentally diverse and largely isolated components of the stream network. Therefore, they argued that headwater communities should follow a species-sorting paradigm since local environmental conditions and species interactions should be the driving forces behind their community structure. Brown and Swan (2010) further claimed that contrary to small streams, the importance of dispersal processes may be higher in higher ordered streams (i.e. mainstem rivers), which are in more central positions within the network. Therefore, they emphasised an increasing importance of dispersal processes in rivers and suggested that the mass effects paradigm should be the dominant structuring force in these habitats, due to the likely strong influence of dispersal on community structure swamping the effects of species interactions and environmental filtering on community structure. In sum, they predicted larger effects of dispersal at more downstream (mainstem) sites and the exclusive role of environmental factors at the most upstream (headwater) sites (Brown \& Swan, 2010; Göthe, Angeler, \& Sandin, 2013). We hereafter refer to these predictions as the network position hypothesis (NPH).

The NPH is a testable hypothesis for gaining a more mechanistic understanding of metacommunity organisation in streams and rivers (Göthe et al., 2013, 2017; Heino, Schmera, \& Erős, 2013; Tonkin, Heino, Sundermann, Haase, \& Jahnig, 2016). However, very few empirical studies have specifically tested the predictions of the NPH, and these have led to rather contradictory conclusions. For instance, Göthe et al. (2013) found that the relative role of environmental and spatial variables depended largely on the time of sampling (spring versus fall) in boreal macroinvertebrate communities. Specifically, they found that in spring, environmental variables had a larger influence in upstream sites, and that spatial variables had an insignificant effect in both upstream and downstream sites (fig. 2 in Göthe et al., 2013). In contrast, in fall, both environmental and spatial variables had a significant effect in both upstream and downstream sites, and dispersal-related signals were only subtly larger in downstream sites. In another study, Tonkin et al. (2016) found that the relative importance of environmental and spatial variables on macroinvertebrate community metrics depended largely on the studied catchment, and were less related to the position within the stream network than local habitat characteristics. In a multi-taxa comparison Göthe et al. (2017) observed the significance of environmental control in the composition of macrophyte, macroinvertebrate and fish communities in headwaters, as well as dispersal-related control of fish species composition in downstream sites. These results, however, are not in full agreement with the predictions of the NPH due to the observed existence of dispersal-related control of species composition of macrophytes in headwaters, the lack of dispersal-related control of macrophyte and macroinvertebrate communities in downstream sites, and the missing environmental control of fish communities in downstream sites. These studies suggest that the relative role of environmental and spatial variables in stream networks is highly context dependent, and cannot be clearly related to network position. Thus, more studies would be necessary to unravel the generality of the NPH in stream metacommunity structuring.

Another highly understudied aspect of the NPH is the range of taxonomic groups for which the hypothesis is valid. Since the dispersal ability of the different taxonomic groups can vary widely, it can be hypothesised that their sensitivity to the geographic distance among sites may also vary. For example, Beisner, Peres-Neto, Lindstrom, Barnett, and Longhi (2006) showed that there are considerable differences in the metacommunity organisation (i.e. in the roles of environmental and spatial variables) of bacteria, phytoplankton, zooplankton and fish communities in Canadian lakes, most likely due to the differences in the size and traits of taxonomic groups. Further, research examining boreal stream communities has indicated that the relative importance of environmental filtering versus dispersal processes can be size- and trait-dependent (Astorga et al., 2012; Sarremejane et al., 2017). In contrast, a review on distance-decay relationships confirmed the importance of the organisms' dispersal ability, but not the size of organisms (Soininen, McDonald, \& Hillebrand, 2007).

In this study, we examined the validity of the NPH using multiple taxonomic groups, namely benthic diatoms, macrophytes, macroinvertebrates and fish. Naturally, there can be remarkable differences in the dispersal ability between passively dispersing plant taxa and that of more mobile animal taxa (Astorga et al., 2012; Göthe et al., 2017; Heino, Grönroos, Soininen, Virtanen, \& Muotka, 2012). In addition, even actively dispersing taxa may show contrasting differences in their dispersal capability. For example, the dispersal of fishes is restricted exclusively to movement within the stream network, while some macroinvertebrate taxa can show both withinstream and overland (out of stream) movements. In this respect, only fish and macroinvertebrate metacommunities with obligate aquatic dispersal mode allow testing the predictions of the NPH in a strict sense, while taxonomic groups with overland dispersal modes, including passively dispersing groups, are less appropriate for this purpose. Interestingly, while several studies have examined the effect of environmental and spatial variables on differently dispersing macroinvertebrate taxa (see Kärnä et al., 2015), to the best of our knowledge, only a single recent study (Göthe et al., 2017) has compared directly the importance of environmental and dispersal-related processes for multiple taxa in light of the NPH. Therefore, due to the increasing importance of the NPH in stream metacommunity ecology and because of its weak, rather contradictory support in the literature, we tested the validity of NPH in an ecoregion where it has never been examined before, and considered theoretical and empirical evidence surrounding the hypothesis.

\section{2 | MATERIALS AND METHODS}

\section{1 | Study sites}

We selected altogether 46 sampling sites in the Danube River catchment in the Pannon ecoregion, Hungary (Figure 1). Sites were 

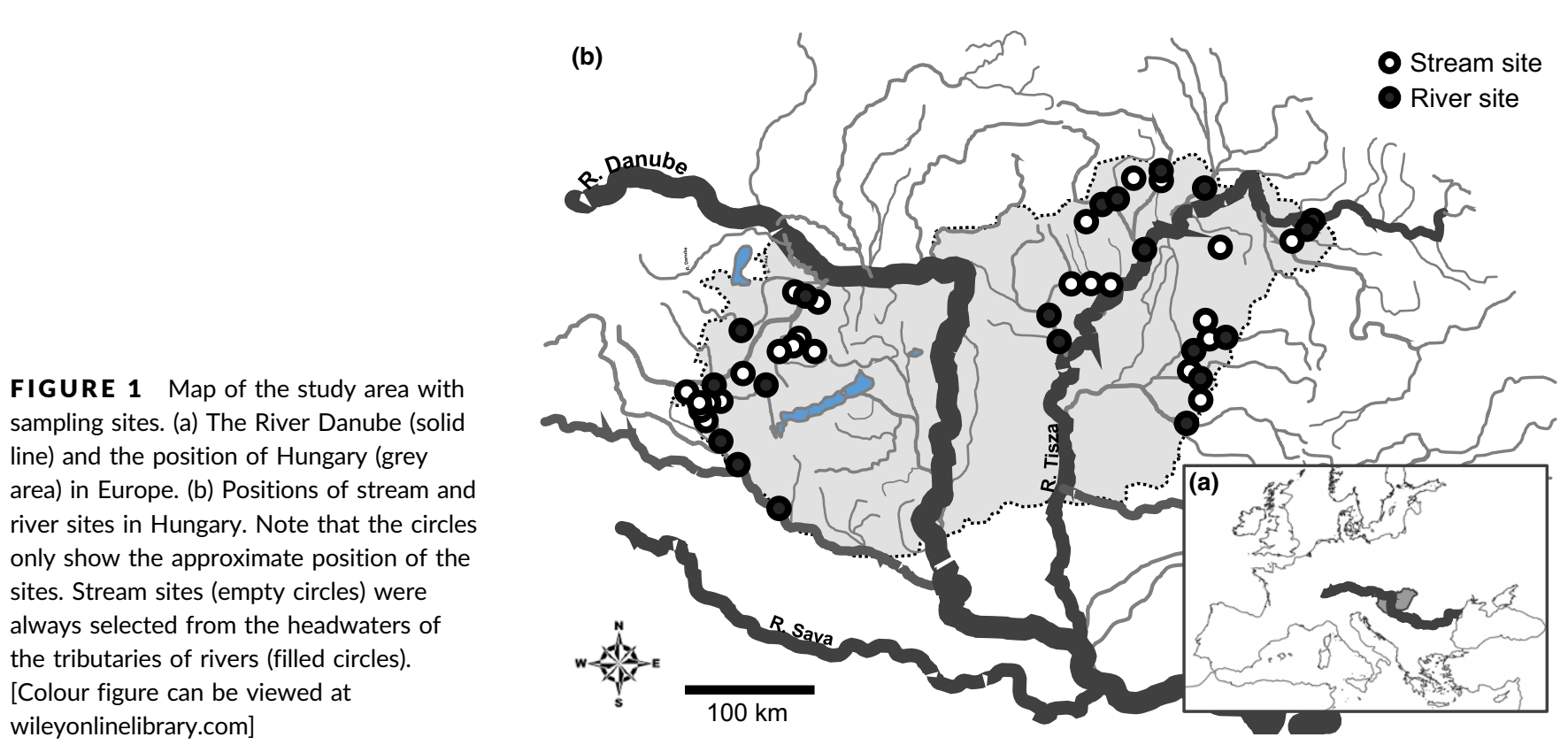

selected from relatively intact catchments in a restricted area of the Middle Danube Basin using geoinformatic maps. Headwater sites (hereafter streams) and more central mainstem sites (hereafter rivers) were represented more or less equally ( 25 stream sites and 21 river sites). It is likely that biotic communities of these sites are operating as a single metacommunity thanks to the common biogeographic history and the identical species pool of the sites, as well as the potential dispersal distance of the organism groups studied (see Erös et al., 2017; Heino et al., 2017; Tonkin et al., 2015, 2017). Site surveys were performed in August 2013, during relatively low water level conditions.

\subsection{Spatial data}

Geographic distance between sites can be quantified in many different ways (Rouquette et al., 2013). Overland distance is the strait line distance between two sites, while watercourse distance takes into account the distances between two sites along the stream network. As the adequacy of overland or watercourse distance for characterising the dispersal of species might strongly depend on the organisms being considered (Astorga et al., 2012; Göthe et al., 2013; Grönroos et al., 2013; Kärnä et al., 2015), we calculated both overland and watercourse distances for stream and river sites separately, even if the correlation between them was high (stream habitat: Mantel $r=.842, p=.001$, river habitat: Mantel $r=.858, p=.001$ ). Overland distance was calculated using the Euclidean distance of site coordinates, while watercourse distance was calculated using topological maps. Mean overland distance among stream sites was slightly smaller than among river sites (mean [and range] for streams: 215.72 [3.07-496.05] km; for rivers: 225.45 [7.56-500.81] km), while mean watercourse distance among stream sites was slightly larger than among river sites (mean [and range] for streams: 830.72 [7.931,553.77] rkm, for rivers: 727.37 [28.09-1,546.76] rkm, where rkm means river kilometre). We believe that such distances allow for detecting dispersal limitation effects even for actively dispersing taxonomic groups like fish.

\section{3 | Environmental variables}

In streams, 6-15 transects (depending on the complexity of the habitat, Erős, Sály, Takács, Specziár, \& Bíró, 2012; Sály et al., 2011) were placed perpendicular to the main channel at each sampling site to characterise the physical features of the environment. Wetted width was measured along each transect. Water depth and current velocity (at 60\% depth) were measured at 3-6 (varied according to the width) equally spaced points along each transect. No transect-based measurements could be conducted in rivers. Here, mean width was measured using the landscape images from Google Earth, while mean velocity and water depth were measured along the sampling reach at $10-15$ points. Visual estimates of percentage substratum cover were assessed following the AQEM protocol (AQEM Consortium, 2002) based on the following inorganic categories: silt (argyllal $<6 \mu \mathrm{m}$ ), sand (psammal: $6 \mu \mathrm{m}$ to $2 \mathrm{~mm})$, akal $(2-20 \mathrm{~mm})$, microlithal $(2-6 \mathrm{~cm})$, mesolithal $(6-20 \mathrm{~cm})$, macrolithal $(20-40 \mathrm{~cm})$ and megalithal $(>40 \mathrm{~cm})$. Water temperature, conductivity, dissolved oxygen content, and $\mathrm{pH}$ were measured with an OAKTON Waterproof PCD 650 portable handheld meter, and the content of nitrogen forms (i.e. nitrite, nitrate, ammonium), calcium and phosphate were measured using field kits (Visocolor ECO, Macherey-Nagel GmbH \& Co. KG., Germany). Altitude was measured in the field using a GPS device (Garmin Montana 650). We used these variables as they provide meaningful information on both the catchment-level and instream characteristics of the habitats, including possible human effects (Erös et al., 2012; Hoeinghaus, Winemiller, \& Birnbaum, 2007; Wang et al., 2003). 


\subsection{Sampling}

\subsection{1 | Diatoms}

Benthic diatoms were collected using the MSZ EN 13946:2003 (2003) standard. At each site, diatoms were removed from an area of c. $10 \mathrm{~cm}^{2}$ from the surface of the at least five rocks with a toothbrush. The material was washed into a plastic container and fixed with Lugol's solution until processing. Approximately $1 \mathrm{~cm}^{3}$ of the material was digested with hydrogen peroxide, rinsed with distilled water, and then mounted on slides using Cargille Meltmount medium (refractive index $=1.7$ ). Diatom valves were identified and counted using Zeiss Axioimager A2 upright microscope at a magnification of $1,000 \times$ using Nomarski contrast and oil immersion. Relative abundance of diatom taxa per sample was analysed by counting at least 400 valves per slide.

\subsubsection{Macrophytes}

Macrophyte assessment was based on the abundance of algae, mosses, liverworts, monocotyledonous and dicotyledonous plant species. All submerged, free floating, amphibious and emerged plants were considered and the assessment also included species attached to or rooted on parts of the bank substratum where they were likely to be submerged for more than $85 \%$ of the year. Species abundance of macrophytes was estimated according to a five-level descriptor scale (1, rare; 2 , occasional; 3 , frequent; 4 , abundant; 5 , very abundant) along a 100-m long transect (Kohler, 1978). Streams were surveyed by wading of the whole stream width; rivers were surveyed by wading along the shore and using a grapnel to collect plant specimens. Macrophyte identification was performed at the species level. Ordinal scaled data of abundance were converted to ratio scale using the mean values of Braun-Blanquet cover classes following Engloner (2012).

\subsection{3 | Macroinvertebrates}

Macroinvertebrates were collected using a standard hand net with frame width of $25 \mathrm{~cm}$ and mesh size $1,000 \mu \mathrm{m}$ following the multihabitat sampling approach developed in the AQEM project (AQEM Consortium 2002; Hering, Moog, Sandin, \& Verdonschot, 2004; Hering et al., 2003). A total of 20 sample units (each sample unit collects from an area of $0.25 \times 0.25 \mathrm{~m}$ ) distributed in a proportional number of the habitats present in 100-m length were sampled by the same operator. Riffle habitats were sampled using the "kick and sweep" technique, while stream edge habitats were sampled by sweeping along vegetation in the stream margins. Field samples were preserved in $70 \%$ ethanol, and processed and sorted in the laboratory. Individuals from 12 taxonomic groups (Gastropoda, Bivalvia, Hirudinea, Crustacea, Ephemeroptera, Odonata, Plecoptera, Heteroptera, Coleoptera, Megaloptera, Trichoptera and Diptera including Chironomidae) were identified and counted under a stereomicroscope to the lowest possible taxonomic level (mostly but not always to species level) by experts using relevant identification keys.

\subsubsection{Fish}

Fish were collected following two different universal electrofishing protocols (see e.g. Oberdorff, Pont, Hugueny, \& Chessel, 2001; Pont et al., 2006). For streams, a battery-powered electrofishing device was used (Hans-Grassl IG 200/2B device, PDC). The crew sampled a 150-m long reach, slowly walking upstream and with a single pass of the whole stream width. For non-wadeable rivers, boat electrofishing was applied with a generator driven device (Hans-Grassl EL64 II GI device, max $7000 \mathrm{~W}, \mathrm{SDC}$ ), slowly moving downstream and electrofishing 500-m long reaches in near shore areas. This division in sampling length between streams and rivers was necessary to optimise sampling effort and to sample fish assemblages representatively and proportionally to the size of the water body (see Erös, 2007). After species-level identification and counting, fish were released into the water at the site of capture.

\subsection{Statistical analyses}

Zero-inflated environmental variables (frequency of zeros larger than $40 \%)$ were excluded from statistical analyses. These were the substratum categories megalithal, macrolithal, mezolithal, mikrolithal and akal. The remaining environmental variables were transformed, if necessary (see Table 1), and of the highly correlated variables $(r>$.7), only the one with lower mean correlation value with the other variables was retained (see Table 1 for the retained variables). T-tests were used to compare environmental variables between stream and river habitats (Table 1). Constrained analysis of principal coordinates (CAP, Anderson \& Willis, 2003) with Euclidean distance (Podani, 2000) was used to test the global separation of stream and river sites using the full set of standardised environmental variables. We ran an ANOVA-like permutation to test for the significance of the separation of stream and river sites.

We tested the NPH by assessing the relative importance of environmental and spatial variables in explaining the variation in the composition of running water communities. To do this, we used a variance partitioning procedure using redundancy analysis ordination (Borcard, Legendre, \& Drapeau, 1992). In this analysis, the response variables were the abundance matrix of running water communities, while environmental and two types of spatial variables (overland and watercourse distances) formed the two explanatory groups of variables. We calculated principal coordinates of neighbourhood matrices to transform spatial (both overland and watercourse) distances to rectangular data that is suitable for constrained ordination. We used forward selection using the ordistep function of vegan (Oksanen et al., 2016) to select significant spatial and environmental variables separately. Species abundances were Hellinger transformed following the recommendation of Legendre and Gallagher (2001). The variance partitioning procedure measures the percent variation (adjusted $R^{2}$ ) explained by different components. The different components following Borcard et al. (1992) were as follows: total explained variation, environmental variation, spatial variation, pure environmental variation (i.e. environmental variation without the effect of spatial 
TABLE 1 Comparison of environmental variables (mean $\pm S E$ ) between stream and river sites

\begin{tabular}{|c|c|c|c|}
\hline Variable & Stream & River & Test \\
\hline \multicolumn{4}{|l|}{ Water chemistry variables } \\
\hline Temperature $\left({ }^{\circ} \mathrm{C}\right)$ & $21.5( \pm 0.70)$ & $23.4( \pm 0.89)$ & $t=1.799, p=.079$ \\
\hline $\mathrm{pH}$ & $8.19( \pm 0.06)$ & $8.47( \pm 0.06)$ & $t=3.135, p=.003$ \\
\hline Conductivity $(\mu \mathrm{S} / \mathrm{cm})$ & $689.8( \pm 69.86)$ & $609.6( \pm 72.22)$ & $t=-7.84, p=.437$ \\
\hline $\begin{array}{l}\text { Nitrite }(\mu \mathrm{g} / \mathrm{L})[\log - \\
\text { transformed] }\end{array}$ & $66.2( \pm 8.37)$ & $62.1( \pm 9.13)$ & $t=0.394, p=.695$ \\
\hline $\begin{array}{l}\text { Nitrate }(\mathrm{mg} / \mathrm{L})[\log x+ \\
0.001 \text {-transformed] }\end{array}$ & $7.00( \pm 0.96)$ & $4.86( \pm 1.05)$ & $t=-0.652, p=.518$ \\
\hline Ammonium (mg/L) & $1.82( \pm 3.16)$ & $4.89( \pm 3.45)$ & $t=-1.097, p=.279$ \\
\hline Calcium (mg/L) & $411.8( \pm 29.74)$ & $386.8( \pm 29.74)$ & $t=-0.601, p=.551$ \\
\hline Phosphorus ( $\mu \mathrm{g} / \mathrm{L})$ & $169.9( \pm 13.56)$ & $121.4( \pm 14.79)$ & $t=-2.373, p=.022$ \\
\hline Phosphate (mg/L) & $1.18( \pm 0.17)$ & $0.73( \pm 0.18)$ & $t=-1.815, p=.076$ \\
\hline \multicolumn{4}{|l|}{ Instream habitat variables } \\
\hline $\begin{array}{l}\text { Sand [Psammal: }>6 \mu \mathrm{m} \text { to } \\
2 \mathrm{~mm} \text { (\%) }\end{array}$ & $18.4( \pm 4.02)$ & $20.2( \pm 4.38)$ & $t=0.303, p=.764$ \\
\hline Silt [Argyllal: $<6 \mu \mathrm{m}$ ] (\%) & $38.0( \pm 7.43)$ & $30.5( \pm 8.11)$ & $t=-0.687, p=.496$ \\
\hline \multicolumn{4}{|l|}{ River habitat variables } \\
\hline Wetted width (m) & $2.84( \pm 4.53)$ & $32.19( \pm 4.95)$ & $t=10.384, p<.001$ \\
\hline $\begin{array}{l}\text { Water depth }(\mathrm{cm})[\text { log- } \\
\text { transformed] }\end{array}$ & $33.7( \pm 7.44)$ & $81.5( \pm 8.12)$ & $t=3.187, p=.003$ \\
\hline Current velocity $(\mathrm{cm} / \mathrm{s})$ & $13.3( \pm 4.13)$ & $42.4( \pm 4.50)$ & $t=3.575, p=.001$ \\
\hline $\begin{array}{l}\text { Altitude (m a.s.l.) [log- } \\
\text { transformed] }\end{array}$ & $155.2( \pm 8.97)$ & $121.6( \pm 9.79)$ & $t=-2.504, p=.016$ \\
\hline
\end{tabular}

variation), pure spatial variation, common environmental and spatial variation, and residual variation not explained by environment and space. Here, we will focus only on pure environmental (hereafter termed environmental), pure spatial (hereafter termed spatial), common environmental and spatial (hereafter termed joint or shared) and residual (unexplained) variation. To get a deeper and more mechanistic insight on the structuring forces of macroinvertebrate communities, which can be relatively clearly distinguished based on their dispersal abilities (e.g. Grönroos et al., 2013; Sarremejane et al., 2017), macroinvertebrate taxa were divided into those that can fly (flying macroinvertebrates) and those that cannot fly (non-flying macroinvertebrates). This grouping allowed to test the response of non-flying macroinvertebrates to watercourse distance and also the response of flying macroinvertebrates to both watercourse and overland distances. All analyses were performed using R (R Core Team, 2016) with the help of the package vegan (Oksanen et al., 2016).

\section{RESULTS}

Streams and rivers differed largely in their size. Streams had an average width and depth of $2.84 \mathrm{~m}$ and $33.7 \mathrm{~cm}$ respectively (Table 1). Rivers had an average width and depth of $32.19 \mathrm{~m}$ and $81.5 \mathrm{~cm}$ respectively. The analyses showed also that the $\mathrm{pH}$ and the current velocity of the water were lower, while phosphorus concentration of the water and the altitude of the sites were higher in streams compared to rivers (Table 1). CAP indicated separation of stream and river habitats based on their environmental characteristics (Figure 2, ANOVA-like permutation $F_{1,44}=5.972, p=.001$ ). The ordination plot showed that the constrained axis (CAP 1) separated stream and river sites (Figure 2).

The biotic communities contained altogether 920 taxa (Table S1). The number of taxa recorded for diatoms, macrophytes, macroinvertebrates and fishes were 264, 252, 354 and 50 respectively. The importance of environmental variables in structuring communities strongly depended on the habitat (streams versus rivers) and the taxonomic group studied (Table S2). Variation partitioning showed that community variation of diatoms was explained both by environmental and spatial variables in streams. In rivers, in contrast, neither environmental nor spatial variables explained a significant proportion of diatom community variation. These patterns were independent of whether overland or watercourse distances were used (Tables 2 and 3). Environmental variables explained a significant proportion of community variation in macrophytes both in streams and rivers using either distance (Tables 2 and 3). The importance of spatial variables in explaining macrophyte community variation was significant only in rivers when using overland distance (Tables 2 and 3). In agreement with the predictions of the $\mathrm{NPH}$, the community variation in macroinvertebrates was explained by environmental variables in streams and by both environmental and spatial variables in rivers independently of whether spatial variables originated from overland or watercourse distances (Tables 2 and 3). Finally, community 


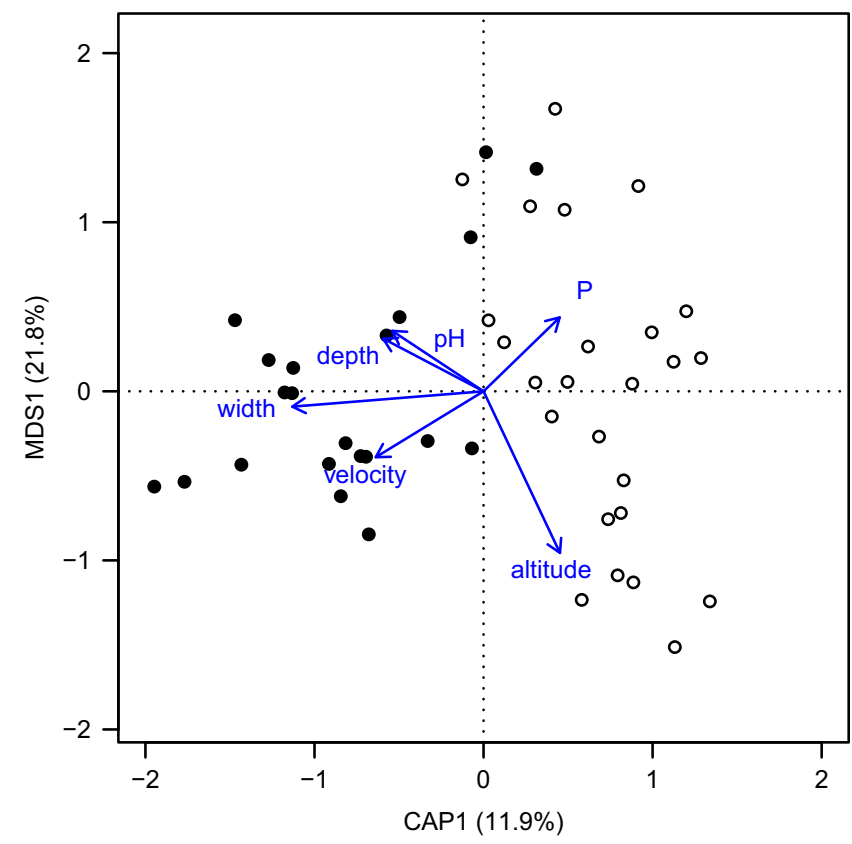

FIGURE 2 Ordination plot of the constrained analysis of principal coordinates (CAP) of the study sites (stream sites: empty circles, river sites: full circles) based on environmental variables. Horizontal axis is the first principal coordinates axis (CAP1) while the vertical axis is the first metric multi-dimensional scaling axis (MDS1). Note that MDS1 is displayed rather than CAP2 because a single axis (CAP1) can separate the two groups of sites. Arrows visualise environmental variables. For clarity, only those environmental variables are displayed which proved to be significant (at $p=.05$ Type I error rate) individually in Table 1. [Colour figure can be viewed at wileyonlinelibrary.com]

variation in fishes was explained by environmental and spatial variables in streams and only by environmental variables in rivers using either distance (Tables 2 and 3).

When overland distance was considered, the proportion of community variation explained by either the environmental or spatial variables was low (varied between $0.5 \%$ and $21.9 \%$ ) and strongly depended on the taxonomic group and habitat studied. In general, environmental variables explained a larger amount of community variation (range: $2.5 \%-21.9 \%$ ) than spatial ones (range: $0.5 \%-8.0 \%$ ) in both streams and rivers (Table 2). The only exception was macrophytes in rivers where spatial variables explained larger variation (8.0\%) than environmental variables (3.4\%, Table 2). As a result of the limited amount of community variation explained by the individual and joint effects of environmental and spatial variables, a high proportion of community variation remained unexplained; the residual variance ranged from $66.3 \%$ to $91.1 \%$ (Table 2). When watercourse distance was considered, the amount of community variation explained by environmental variables (range: 3.4\%-20.9\%) was always larger than that explained by spatial variables (range: $0.0 \%$ $12.6 \%)$ independent of the taxonomic group and habitat studied, and residual variance was high (60.9\%-93.6\%; Table 3).

The division of macroinvertebrate taxa into flying and non-flying groups showed that these groups were influenced by different environmental variables both in stream and river habitats, but the explained variance was very low in all cases (Table 4). The variance of non-flying macroinvertebrate groups was explained exclusively by environmental variables in both streams and rivers. Similarly, flying macroinvertebrates were influenced by environmental variables both in streams and rivers (Table 4). However, the importance of spatial variables in rivers depended on whether overland or watercourse distance was considered (Table 4).

\section{DISCUSSION}

This study examined the relative role of environmental (nicherelated) and dispersal-related processes in structuring metacommunities in dendritic stream networks. The NPH, which postulated the primary role of environmental processes in upstream sites as well as the joint effects of environmental and dispersal-related processes in mainstem riverine sections, received limited support in our multi-taxa comparison.

Brown and Swan (2010) examined macroinvertebrate communities when conceptualising the NPH for explaining metacommunity structuring in stream networks. However, subsequent tests of the $\mathrm{NPH}$ with macroinvertebrate communities have yielded mixed results. For example, Göthe et al. (2013) highlighted that the timing of sampling can strongly influence the relative role of environmental and spatial variables in explaining metacommunity patterns. Göthe et al. (2017) observed only the importance of environmental processes in both more isolated upstream and less isolated downstream habitats. In addition, Tonkin et al. (2016) emphasised that individual systems might show considerable variability in the relative importance of environmental and spatial variables. Our results on macroinvertebrates are in agreement with the predictions of NPH since we found that stream communities were structured by environmental variables while river communities by both environmental and dispersal-related processes. Further, splitting the macroinvertebrate community into flying and non-flying taxa revealed significant spatial effects only in rivers. Interestingly, however, this effect was only observed only for flying and not for non-flying taxa; a result which is challenging to explain with the differences in the spatial isolation of headwater versus mainstem habitats.

Other taxonomic groups showed less corresponding results with the predictions of the NPH. Macrophyte communities supported the predictions of NPH only when overland distance was considered, while diatom and fish communities only exhibited significant spatial processes in streams. Results of these latter two taxonomic groups thus clearly run counter with the predictions of the NPH. Besides these findings, several other studies suggest that the role of environmental and dispersal-related processes can differ from the predictions of the NPH. For example, Heino et al. (2012) found that the significance of environmental processes was drainage dependent in structuring diatom and bryophyte communities in boreal headwaters. Interestingly, however, community structure could not be related to potential environmental predictors in each case. In addition, Göthe et al. (2017) detected the importance of dispersal processes in 
TABLE 2 Variance partitioning of the pure effects of environmental, spatial (overland distance), shared and residual variance for four taxonomic groups in streams and in rivers

\begin{tabular}{|c|c|c|c|c|c|c|c|c|}
\hline \multirow{2}{*}{$\begin{array}{l}\text { Habitat } \\
\text { Taxonomic group }\end{array}$} & \multicolumn{3}{|c|}{ Environmental } & \multicolumn{3}{|l|}{ Spatial } & \multirow{2}{*}{$\begin{array}{l}\text { Shared } \\
\text { Adj. } R^{2}\end{array}$} & \multirow{2}{*}{$\begin{array}{l}\text { Residual } \\
\text { Adj. } R^{2}\end{array}$} \\
\hline & Adj. $R^{2}$ & Pseudo-F & $p$ & Adj. $R^{2}$ & Pseudo-F & $p$ & & \\
\hline \multicolumn{9}{|l|}{ Stream } \\
\hline Macrophytes & .064 & 1.531 & .002 & .018 & 1.151 & .155 & .074 & .843 \\
\hline Macroinvertebrates & .151 & 1.979 & .001 & .005 & 1.074 & .344 & .087 & .756 \\
\hline \multicolumn{9}{|l|}{ River } \\
\hline Diatoms & .025 & 1.245 & .089 & .019 & 1.183 & .163 & .045 & .911 \\
\hline Macrophytes & .034 & 1.657 & .022 & .080 & 1.576 & .002 & .007 & .878 \\
\hline Macroinvertebrates & .068 & 1.725 & .005 & .061 & 1.687 & .002 & .045 & .796 \\
\hline Fish & .219 & 3.985 & .001 & .019 & 1.271 & .224 & .097 & .663 \\
\hline
\end{tabular}

TABLE 3 Variance partitioning of the pure effects of environmental, spatial (watercourse distance), shared and residual variance for four taxonomic groups in streams and in rivers

\begin{tabular}{|c|c|c|c|c|c|c|c|c|}
\hline \multirow{2}{*}{$\begin{array}{l}\text { Habitat } \\
\text { Taxonomic group }\end{array}$} & \multicolumn{3}{|c|}{ Environmental } & \multicolumn{3}{|l|}{ Spatial } & \multirow{2}{*}{$\begin{array}{l}\text { Shared } \\
\text { Adj. } R^{2}\end{array}$} & \multirow{2}{*}{$\begin{array}{l}\text { Residual } \\
\text { Adj. } R^{2}\end{array}$} \\
\hline & Adj. $R^{2}$ & Pseudo-F & $p$ & Adj. $R^{2}$ & Pseudo-F & $p$ & & \\
\hline \multicolumn{9}{|l|}{ Stream } \\
\hline Macrophytes & .108 & 1.973 & .001 & .004 & 1.114 & .275 & .030 & .856 \\
\hline Macroinvertebrates & .156 & 1.898 & .001 & -.004 & 0.786 & .851 & .082 & .766 \\
\hline \multicolumn{9}{|l|}{ River } \\
\hline Diatoms & .034 & 1.335 & .051 & .026 & 1.261 & .125 & .034 & .903 \\
\hline Macrophytes & .043 & 1.877 & .008 & .021 & 1.443 & .064 & -.002 & .936 \\
\hline Macroinvertebrates & .090 & 1.996 & .005 & .072 & 2.066 & .006 & .029 & .815 \\
\hline Fish & .209 & 4.441 & .001 & .032 & 1.454 & .126 & .108 & .649 \\
\hline
\end{tabular}

TABLE 4 Variance partitioning of the pure effects of environmental, spatial, shared and residual variance for non-flying (NF) and flying (F) macroinvertebrate groups in streams and in rivers. Watercourse (W) distance was used for non-flying macroinvertebrates, while both overland (O) and watercourse (W) distance was used for flying macroinvertebrate groups

\begin{tabular}{|c|c|c|c|c|c|c|c|c|c|}
\hline \multirow{2}{*}{$\begin{array}{l}\text { Habitat } \\
\text { Group }\end{array}$} & \multirow[b]{2}{*}{ Distance } & \multicolumn{3}{|c|}{ Environmental } & \multicolumn{3}{|l|}{ Spatial } & \multirow{2}{*}{$\begin{array}{l}\text { Shared } \\
\text { Adj. } R^{2}\end{array}$} & \multirow{2}{*}{$\begin{array}{l}\text { Residual } \\
\text { Adj. } R^{2}\end{array}$} \\
\hline & & Adj. $R^{2}$ & Pseudo-F & $p$ & Adj. $R^{2}$ & Pseudo- $F$ & $p$ & & \\
\hline \multicolumn{10}{|l|}{ Stream } \\
\hline F macroinvertebrates & $\mathrm{O}$ & .096 & 1.522 & .009 & -.002 & 0.812 & .858 & .226 & .773 \\
\hline F macroinvertebrates & W & .249 & 2.541 & .001 & .004 & 0.784 & .725 & .000 & .746 \\
\hline NF macroinvertebrates & W & .093 & 2.038 & .005 & .018 & 1.399 & .148 & .144 & .855 \\
\hline $\mathrm{F}$ macroinvertebrates & $\mathrm{O}$ & .042 & 1.920 & .007 & .053 & 2.012 & .005 & .129 & .870 \\
\hline F macroinvertebrates & W & .072 & 2.519 & .003 & -.001 & 0.874 & .692 & .000 & .939 \\
\hline
\end{tabular}

structuring headwater macrophyte communities and did not detect the importance of dispersal processes in structuring mainstem fish communities. These findings, complemented by our results, suggest that the NPH cannot be regarded as a general hypothesis that describes the structuring of metacommunities in stream networks, and especially not in a taxon-independent manner. In the 
forthcoming paragraphs, we thus discuss possible explanations of the observed patterns in light of the predictions of the NPH.

Streams are dynamic ecosystems with considerable spatial and temporal variability (Poff et al., 1997). Although stream dwelling communities are evolutionarily well adapted to such conditions, stochasticity in abiotic (e.g. floods, droughts) and biotic (e.g. extinction, colonisation) factors may yield considerable community variation (Townsend, 1989). Thus, not surprisingly, the majority of the variance in our study was unexplained, similar to the findings of other studies (e.g. Heino et al., 2012; Siqueira et al., 2012). In fact, Göthe et al. (2013, 2017), who at least partially supported the predictions of the $\mathrm{NPH}$, reported a large proportion ( $>50 \%$ ) of unexplained variance in their study. The extreme stochasticity of stream systems might provide an explanation for the few empirical studies that support the predictions of the NPH.

Beside the extreme spatial and temporal variability in stream systems, which makes testing theory with field data challenging, we believe that assumptions of the NPH also need more critical evaluations. Again, key predictions of the NPH are (1) that headwater sites are more isolated than mainstem (more downstream) sites, and (2) that the role of environmental processes (i.e. species-sorting mechanisms) is more pronounced in isolated headwater sites, than at less isolated downstream (mainstem) sites, where dispersal driven processes (i.e. mass effect mechanisms) have more critical importance. First, headwaters are not necessarily more isolated physically in the landscape than mainstem sites, since, due to the dendritic structure of stream networks, upstream segments can be very far or very close to each other in the landscape. Therefore, the importance of dispersal-related processes may vary over a much wider scale in upstream compared to downstream segments (Heino et al., 2015). It is likely that such scale dependence in the spatial distribution of sampling sites (i.e. spatial extent) can largely influence the relative effects of environmental and dispersal processes in both headwater and mainstem metacommunities. Supporting our argument, significance of spatial processes has been indicated for a variety of taxa and in a variety of stream systems, including headwaters (Erös et al., 2012, 2017; Maloney \& Munguia, 2011; Paavola et al., 2006).

Second, beside the direct effect of physical distance, the role of isolation effects is also influenced by dispersal traits, and therefore by the trait-based composition of the metacommunity (De Bie et al., 2012; Soininen, Jamoneau, Rosebery, \& Passy, 2016). For example, taxa with overland dispersal can be less influenced by the spatial structure of the stream network (e.g. Razeng et al., 2016), and in the case of overland dispersal, headwater sites may not necessarily be more isolated than downstream ones. In agreement with this argument, a recent study on boreal stream macroinvertebrates showed that weak flyers were constrained in most isolated sites whereas strong flyers were not restricted by river network structure and were mainly assembled through mass effect mechanisms (Sarremejane et al., 2017). In fact, many diatom, macrophyte and macroinvertebrate species are capable of overland dispersal (De Bie et al., 2012; Soininen et al., 2016). Thus, both overland and watercourse distances can at least partly describe their among-site movements
(Castillo-Ercriva et al., 2016). Not surprisingly, we obtained contradictory results on the importance of spatial and environmental variables depending on the distance measure used for specific taxa (here macrophytes). By contrast, the movement of fish is restricted exclusively to the stream network. Fish metacommunities are thus probably the most ideal organisms for testing the predictions of the NPH. Results on fish show however, that both headwater and mainstem metacommunities can be influenced both by environmental and spatial factors, and overall, that the role of dispersal-related processes do not necessarily increase downstream. These findings on fish thus run counter with the predictions of the NPH, too.

Third, predicting that increasing isolation should result in stronger environmental associations (i.e. increased importance of speciessorting mechanisms), and a decrease in dispersal driven processes (see Brown \& Swan, 2010; Driscoll \& Lindenmayer, 2009) is logical. However, dispersal limitation (i.e. restricted movement among sites) may increase the importance of neutral or chance effects (i.e. stochasticity in population dynamics among sites) in community organisation (Lowe \& McPeek, 2014). Consequently, if headwater segments are more isolated than downstream sites (Brown \& Swan, 2010), the effects of neutral processes should be more pronounced upstream, which may be indicated by the increased importance of spatial variables upstream. The greater influence of dispersal-related processes (here, a decay in community similarity with spatial distance among sites) was also observed in hydrologically isolated intermittent sites, compared with hydrologically well connected perennial sites in the catchments of Daly and Fitzroy Rivers, Australia (Warfe et al., 2013). This result shows just the opposite what the NPH predicts.

Fourth, environmental heterogeneity of headwater streams and more downstream mainstem rivers may not necessarily differ (Erös et al., 2017). Therefore, not considering dispersal driven processes, the effect of environmental variables (i.e. the strength of niche-based species-sorting mechanisms) may not necessarily change along the upstream-downstream gradient. Further, dispersal driven spatial structuring (e.g. mass effect mechanisms, dispersal limitation) may not only occur in downstream mainstem habitats, but also in headwater streams (e.g. Cetra, Petrere, \& Barrella, 2017; Erős et al., 2012; Heino et al., 2012; Mykrä, Heino, \& Muotka, 2007). Therefore, the interplay of environmental and dispersal driven processes may influence metacommunity organisation in both headwater and mainstem habitats in a variety of ways (Heino et al., 2015).

Fifth, quantifying the role of environmental and dispersal-related processes is not always straightforward with presently used pattern detecting methods, which may also hinder the exact determination of environmental and dispersal-related processes. For example, using variance partitioning analyses on fish metacommunities, Sály and Erös (2016) demonstrated that the relative role of environmental and spatial variables can depend largely both on the number of samples and the distribution of sites within the stream network. The application of variance partitioning can be especially problematic if environmental and spatial variation largely overlap (Gilbert \& Bennett, 2010; Legendre \& Legendre, 2012). Distance-decay analyses, which are used to test linear changes in community similarity with 
spatial distance, cannot really be used to unconvincingly separate the pure and shared effects of environmental and spatial predictors (Beisner et al., 2006; De Bie et al., 2012). Further, a simple measurement of isolation in the stream network can be also misleading. Recent graph based indices provide an excellent tool for the quantification of structural connectivity in stream networks (Erős et al., 2012), but in fact, these measures can be used only as a crude proxy of functional connectivity, and in addition they are best applicable to obligate aquatic dispersers, such as fishes. Consideration of overland dispersal (Campbell \& Mclntosh, 2013) and features of the between site habitat matrix (Erös \& Grant, 2015) can also be important for the correct determination of isolation in a taxa specific manner. Therefore, methodologies that better consider isolation and dispersal effects are needed for a better understanding of the role of environmental and spatial effects in stream networks (Downes, Lancester, Glaister, \& Bovill, 2017; Sarremejane et al., 2017). Overall, stating that headwater streams are more isolated components of the landscape than more downstream habitats is a too simplistic assumption (i.e. depends largely on the context of the study), because the degree of isolation can depend on many factors including scale, spatiotemporal heterogeneity of the focal habitat as well as the matrix habitat, and dispersal traits of specific taxa.

In conclusion, our tests with multiple taxa provided only weak support for the NPH. We believe that the postulation of the NPH on the role of environmental and dispersal-related processes in headwater and mainstem communities is too simplistic, and cannot address the possible range of patterns and processes that can occur in stream systems. Environmental heterogeneity of the habitat, isolation effects and trait based characteristics of the community jointly shape metacommunity dynamics in stream networks in a complex and context dependent manner (Campbell \& McIntosh, 2013; Heino et al., 2015; Tonkin et al., 2016). Therefore, presently used analytical methods may be inadequate to unequivocally reveal processes behind the observed patterns. Overall, we believe that the NPH of Brown and Swan (2010) was highly influential in thinking in a metacommunity context in stream networks. However, future, more detailed studies should address how different forms of isolation effects influence the metacommunity organisation of individual taxa and trait groups, which may lead to a more mechanistic understanding of the role of environmental and spatial processes in these unique dendritic systems.

\section{ACKNOWLEDGMENTS}

This work was supported by the OTKA K104279 and the GINOP 2.3.3-15-2016-00019 grants.

\section{REFERENCES}

Altermatt, F. (2013). Diversity in riverine metacommunities: A network perspective. Aquatic Ecology, 47, 365-377.

Anderson, M. J., \& Willis, T. J. (2003). Canonical analysis of principal coordinates: A useful method of constrained ordination for ecology. Ecology, 84, 511-525.
AQEM Consortium (2002). Manual for the application of the AQEM method. A comprehensive method to assess European streams using benthic macroinvertebrates, developed for the purpose of the Water Framework Directive. Version 1.0.

Astorga, A., Oksanen, J., Soininen, J., Virtanen, R., Luoto, M., \& Muotka, T. (2012). Distance decay of similarity in stream communities: Do macro- and microorganisms follow the same rules? Global Ecology and Biogeography, 21, 365-375.

Beisner, B. E., Peres-Neto, P. R., Lindstrom, E., Barnett, A., \& Longhi, M. L. (2006). The role of dispersal in structuring lake communities from bacteria to fish. Ecology, 87, 2895-2991.

Borcard, D., Legendre, P., \& Drapeau, P. (1992). Partialling out the spatial component of ecological variation. Ecology, 73, 1045-1055.

Brown, B. L., \& Swan, C. M. (2010). Dendritic network structure constrains metacommunity properties in riverine ecosystems. Journal of Animal Ecology, 79, 571-580.

Campbell Grant, E. H., Lowe, W. H., \& Fagan, W. F. (2007). Living in the branches: Population dynamics and ecological processes in dendritic networks. Ecology Letters, 10, 165-175.

Campbell, R. E., \& Mclntosh, A. R. (2013). Does isolation and local habitat jointly limit the structure of stream invertebrate assemblages? Freshwater Biology, 58, 128-141.

Castillo-Ercriva, A., Rueda, J., Zamora, L., Hernandez, R., del Moral, M., \& Mesquita-Joanes, F. (2016). The role of watercourse versus overland dispersal and niche effects on ostracod distribution in Mediterranean streams (eastern Iberian Penisula). Acta Oecologica, 73, 1-9.

Cetra, M., Petrere, J. M., \& Barrella, W. (2017). Relative influences of environmental and spatial factors on stream fish assemblages in Brazilian Atlantic Rainforest. Fisheries Management and Ecology, 24, 139-145.

Cottenie, K. (2005). Integrating environmental and spatial processes in ecological community dynamics. Ecology Letters, 8, 1175-1182.

De Bie, T., De Meester, L., Brendonck, L., Martens, K., Goddeeris, B., Ercken, D., ... Declerck, S. A. J. (2012). Body size and dispersal mode as key traits determining metacommunity structure of aquatic organisms. Ecology Letters, 15, 740-747.

Driscoll, D. A., \& Lindenmayer, D. B. (2009). Empirical tests of metacommunity theory using an isolation gradient. Ecological Monographs, 79, 485-501.

Downes, B. J., Lancester, J., Glaister, A., \& Bovill, W. D. (2017). A fresh approach reveals how dispersal shapes metacommunity structure in a human-altered landscape. Journal of Applied Ecology, 54, 588-598.

Engloner, A. (2012). Alternative ways to use and evaluate Kohler's ordinal scale to assess aquatic macrophyte abundance. Ecological Indicators, 20, 238-243.

Erös, T. (2007). Partitioning biodiversity of riverine fish: The role of habitat types and non-native species. Freshwater Biology, 52, $1400-1415$.

Erős, T., Sály, P., Takács, P., Specziár, A., \& Bíró, P. (2012). Temporal variability in the spatial and environmental determinants of functional metacommunity organization - Stream fish in a human modified landscape. Freshwater Biology, 57, 1914-1928.

Erös, T., \& Grant, E. H. C. (2015). Unifying research on the fragmentation of terrestrial and aquatic habitats: Patches, connectivity and the matrix in riverscapes. Freshwater Biology, 60, 1487-1501.

Erős, T., Takács, P., Specziár, A., Schmera, D., \& Sály, P. (2017). Effect of landscape context on fish metacommunity structuring in stream networks. Freshwater Biology, 62, 215-228.

Gilbert, B., \& Bennett, J. R. (2010). Partitioning variation in ecological communities: Do the numbers add up? Journal of Applied Ecology, 47, 1071-1082.

Gilpin, M. E., \& Hanski, I. A. (1991). Metpopulation dynamics. Empirical and theoretical investigations. London: Academic Press. 
Göthe, E., Angeler, D. G., \& Sandin, L. (2013). Metacommunity structure in a small boreal stream network. Journal of Animal Ecology, 82, 449458.

Göthe, E., Baattrup-Pedersen, A., Wiberg-Larsen, P., Graeber, D., Kristensen, E. A., \& Friberg, N. (2017). Environmental and spatial controls of taxonomic versus trait composition of stream biota. Freshwater Biology, 62, 397-413.

Grönroos, M., Heino, J., Siqueira, T., Ladeiro, V. L., Kotanen, J., \& Bini, L. M. (2013). Metacommunity structuring in stream networks: Roles of dispersal mode, distance type, and regional environmental context. Ecology and Evolution, 3, 4437-4487.

Heino, J., Grönroos, M., Soininen, J., Virtanen, R., \& Muotka, T. (2012). Context dependency and metacommunity structuring in boreal headwater streams. Oikos, 121, 537-544.

Heino, J., Melo, A. S., Siqueira, T., Soininen, J., Valanko, S., \& Bini, L. M. (2015). Metacommunity organization, spatial extent and dispersal in aquatic systems: Patterns, processes and prospects. Freshwater Biology, 60, 845-869.

Heino, J., Schmera, D., \& Erős, T. (2013). A macroecological perspective of traits patterns in stream communities. Freshwater Biology, 58, 1539-1555.

Heino, J., Soininen, J., Alahuhta, J., Lappalainen, J., \& Virtanen, R. (2017). Metacommunity ecology meets biogeography: Effects of geographical region, spatial dynamics and environmental filtering on community structure in aquatic organisms. Oecologia, 183, 121-137.

Hering, D., Buffagni, A., Moog, O., Sandin, L., Sommerhäuser, M., Stubauer, I., ... Zahrádková, S. (2003). The development of a system to assess the ecological quality of streams based on macroinvertebrates -Design of the sampling programme within the AQEM project. International Review of Hydrobiology, 88, 345-361.

Hering, D., Moog, O., Sandin, L., \& Verdonschot, P. F. M. (2004). Overview and application of the AQEM assessment system. Hydrobiologia, 516, 1-20.

Hoeinghaus, D. J., Winemiller, K. O., \& Birnbaum, J. S. (2007). Local and regional determinants of stream fish assemblage structure: Inferences based on taxonomic vs. functional groups. Journal of Biogeography, 34, 324-338.

Kärnä, O. M., Grönroos, M., Antikainen, H., Hjort, J., Ilmonen, J., Paasivirta, L., \& Heino, J. (2015). Inferring the effects of potential dispersal routes on the metacommunity structure of stream insects: As the crow flies, as the fish swims or as the fox runs? Journal of Animal Ecology, 84, 1342-1353.

Kohler, A. (1978). Methoden der Kartierung von Flora und Vegetation von Süßwasserbiotopen. Landschaft und Stadt, 10, 73-85.

Legendre, P., \& Gallagher, E. D. (2001). Ecologically meaningful transformations for ordination of species data. Oecologia, 129, 271-280.

Legendre, P., \& Legendre, L. (2012). Numerical ecology (third English edition). Amsterdam: Elsevier.

Leibold, M. A., Holyolak, M., Mouquet, N., Amarasekare, P., Chase, J. M., Hoopes, M. F., ... Gonzalez, A. (2004). The metacommunity concept: A framework for multipli-scale community ecology. Ecology Letters, 7 , 601-613.

Logue, J. B., Mouquet, N., Peter, H., \& Hillebrand, H. (2011). Empirical approaches to metacommunities: A review and comparison with theory. Trends in Ecology \& Evolution, 26, 482-491.

Lowe, W. H., \& McPeek, M. A. (2014). Is dispersal neutral? Trends in Ecology \& Evolution, 29, 444450.

Maloney, K. O., \& Munguia, P. (2011). Distance decay of similarity in temperate aquatic communities: Effects of environmental transition zones, distance measures and life histories. Ecography, 34, 287-295.

Meynard, C. N., Lavergne, S., Boulangeat, I., Garraud, L., Van Es, J., Mouquet, N., \& Thuiller, W. (2013). Disentangling the drivers of metacommunity structure across spatial scales. Journal of Biogeography, 40, 1560-1571.
MSZ EN 13946:2003 (2003). Vízminőség. Útmutató folyók bentikus kovamoszatainak általános mintavételéhez és mintaelókészitéséhez [Water Quality. Guidance to the sampling and sample preparation of benthic diatoms].

Mykrä, H., Heino, J., \& Muotka, T. (2007). Scale-related patterns in the spatial and environmental components of stream macroinvertebrate assemblage variation. Global Ecology \& Biogeography, 16, 149-159.

Oberdorff, T., Pont, D., Hugueny, B., \& Chessel, D. (2001). A probabilistic model characterizing fish assemblages of French rivers: A framework for environmental assessment. Freshwater Biology, 46, 399-415.

Oksanen, J., Blanchet, G., Fiendly, M., Kindt, R., Legendre, P., McGlinn, D., ... Wagner, H. (2016). vegan: Community Ecology Package. R package version 2.4-0. Retrieved from https://CRAN.R-project.org/packa ge=vegan.

Paavola, R., Muotka, T., Virtanen, R., Heino, J., Jackson, D., \& MakiPetays, A. (2006). Spatial scale affects community concordance among fishes, benthic macroinvertebrates, and bryophytes in streams. Ecological Applications, 16, 368-379.

Podani, J. (2000). Introduction into the exploration of multivariate biological data. Leiden: Backhuys.

Poff, N. L., Allan, D. J., Bain, M. B., Karr, J. R., Prestegaard, K. L., Richter, B. D., ... Stromberg, J. C. (1997). The natural flow regime. BioScience, 47, 769-784.

Pont, D., Hugueny, B., Beier, U., Goffaux, D., Melcher, A., Noble, R., ... Schmutz, S. (2006). Assessing river biotic condition at a continental scale: A European approach using functional metrics and fish assemblages. Journal of Applied Ecology, 43, 70-80.

$R$ Core Team (2016). R: A language and environment for statistical computing, version 3.2.5. Vienna, Austria: R Foundation for Statistical Computing. Retrieved from https://www.R-project.org/

Razeng, E., Morán-Ordóñez, A., Brim Box, J., Thompson, R., Davis, J., \& Sunnucks, P. (2016). A potential role for overland dispersal in shaping aquatic invertebrate communities in arid regions. Freshwater Biology, 61, 745-757.

Rouquette, J. R., Dallimer, M., Armsworth, P. R., Gaston, K. J., Maltby, L., \& Warren, P. H. (2013). Species turnover and geographic distance in an urban river network. Diversity and Distributions, 19, 1429-1439.

Sály, P., Takács, P., Kiss, I., Bíró, P., \& Erős, T. (2011). The relative influence of spatial context and catchment- and site-scale environmental factors on stream fish assemblages in a human-modified landscape. Ecology of Freshwater Fish, 20, 251-262.

Sály, P., \& Erös, T. (2016). Effect of field sampling design on variation partitioning in a dendritic stream network. Ecological Complexity, 28, 187-199.

Sarremejane, R., Mykrä, H., Bonada, N., Aroviita, J., \& Muotka, T. (2017). Habitat connectivity and dispersal ability drive the assembly mechanisms of macroinvertebrate communities in river networks. Freshwater Biology, 62, 1073-1082.

Shurin, J. B. (2000). Dispersal limitation, invasion resistance, and the structure of pond zooplakton communities. Ecology, 81, 3074-3086.

Siqueira, T., Bini, L. M., Roque, F. O., Prpinelli, M., Ramos, R. C., Marques Coucerio, S. R., ... Cotennie, K. (2012). Common and rare species respond to similar niche processes in macroinvertebrate metacommunities. Ecography, 35, 183-192.

Soininen, J., Jamoneau, A., Rosebery, J., \& Passy, S. I. (2016). Global patterns of species and trait composition in diatoms. Global Ecology and Biogeography, 25, 940-950.

Soininen, J., McDonald, R., \& Hillebrand, H. (2007). The distance decay of similarity in ecological communities. Ecography, 30, 3-12.

Tonkin, J. D., Heino, J., Sundermann, A., Haase, P., \& Jahnig, S. C. (2016). Context dependency in biodiversity patterns of central German stream metacommunities. Freshwater Biology, 61, 607-620.

Tonkin, J. D., Shah, R. D. T., Shah, D. N., Hoppeler, F., Jahnig, S. C., \& Pauls, S. U. (2017). Metacommunity structuring in Himalayan streams 
over large elevational gradients: The role of dispersal routes and niche characteristics. Journal of Biogeography, 44, 62-74.

Tonkin, J. D., Sundermann, A., Jahnig, S. C., \& Haase, P. (2015). Environmental controls on river assemblages at the regional scale: An application of the elements of metacommunity structure framework. PLoS ONE, 10, e0135450.

Townsend, C. R. (1989). The patch dynamics concept of stream community ecology. Journal of the North American Benthological Society, 8 , 36-50.

Urban, M. C., Leibold, M. A., Amarasekare, P., De Meester, L., Gumulkiewicz, R., Hochberg, M. E., ... Wade, M. J. (2008). The evolutionary ecology of metacommunities. Trends in Ecology \& Evolution, 23, 311 317.

Wang, L., Lyons, J., Rasmussen, P., Seelbach, P., Simon, T., Wiley, M., ... Stewart, P. M. (2003). Watershed, reach, and riparian influences on stream fish assemblages in the Northern Lakes and Forest Ecoregion, U.S.A. Canadian Journal of Fisheries and Aquatic Sciences, 60, 491505.

Warfe, D. M., Pettit, N. E., Magierowski, R. H., Pusey, B. J., Davies, P. M., Douglas, M. M., \& Bunn, S. E. (2013). Hydrological connectivity structures concordant plant and animal assemblages according to niche rather than dispersal processes. Freshwater Biology, 58, 292-305.
Wienegardner, A. K., Jones, B. K., Ng, I. S. Y., Siqueira, T., \& Cottenie, K. (2012). The terminology of metacommunity ecology. Trends in Ecology \& Evolution, 27, 253-254.

\section{SUPPORTING INFORMATION}

Additional Supporting Information may be found online in the supporting information tab for this article.

How to cite this article: Schmera D, Árva D, Boda P, et al. Does isolation influence the relative role of environmental and dispersal-related processes in stream networks? An empirical test of the network position hypothesis using multiple taxa. Freshwater Biol. 2018;63:74-85.

https://doi.org/10.1111/fwb.12973 